\title{
HealthCare-Associated Infections Among NEONATES IN BRAZIL
}

\author{
Carmem Lúcia Pessoa-Silva, MD; Rosana Richtmann, MD; Roseli Calil, MD; Rosana Maria Rangel Santos, MD; \\ Maria Luiza M. Costa, RN; Ana Cristina Cisne Frota, MD; Sergio Barsanti Wey, MD
}

\begin{abstract}
OBJECTIVE: To describe the epidemiology of healthcare-associated infections (HAIs) among neonates.

DESIGN: Prospective surveillance of HAIs was conducted during 2 years. Infections beginning within 48 hours of birth were defined as HAIs of maternal origin. Death occurring during an active episode of HAI was considered related to HAI. cities.

SETTING: Seven neonatal units located in three Brazilian

PATIENTS: All admitted neonates were included and observed until discharge.

RESULTS: Twenty-two percent of 4,878 neonates had at least one HAI. The overall incidence density was 24.9 per 1,000 patient-days, and $28.1 \%$ of all HAIs were maternally acquired. HAI rates ranged from $12.3 \%$ in the group with a birth weight (BW) of more than $2,500 \mathrm{~g}$ to $51.9 \%$ in the group with a BW of $1,000 \mathrm{~g}$ or

less. The main HAIs were bloodstream infection (BSI) and pneumonia. Coagulase-negative staphylococci, Enterobacter species, Staphylococcus aureus, and Klebsiella pneumoniae were the main pathogens. Forty percent of all deaths were related to HAI. Central venous catheter (CVC)-associated BSIs per 1,000 CVCdays ranged from 17.3 (BW, 1,501 to 2,500 g; device utilization [DU], 0.11) to 34.9 (BW, $\leqslant 1,000 \mathrm{~g} ; \mathrm{DU}, 34.92)$. Ventilator-associated pneumonia per 1,000 ventilator-days ranged from $7.0(\mathrm{BW}, \leqslant$ $1,000 \mathrm{~g}$; DU, 0.34) to 9.2 (BW, 1,001 to $1,500 \mathrm{~g}$; DU, 0.14).

CONCLUSIONS: The high proportion of HAIs of maternal origin highlights perinatal care issues in Brazil and the need to improve the diagnosis of neonatal HAIs. The very low BW group and device-associated infections should be priorities for prevention strategies in this population (Infect Control Hosp Epidemiol 2004;25:772-777).
\end{abstract}

The intensive use of medical devices for and the immaturity of the immunologic system of neonates admitted to neonatal units increase their risk of developing healthcare-associated infections. ${ }^{1}$ Nosocomial infections affect up to $30 \%$ of neonates, ${ }^{2-6}$ and rates can be more than 5 times higher in this population compared with older children. ${ }^{3,4} \mathrm{~A}$ better understanding of the epidemiology of neonatal healthcare-associated infections may lead to prevention strategies in neonatal units and therefore reduced morbidity and mortality related to these infections.

In Brazil, $60 \%$ of deaths among children in their first year occur during the neonatal period. However, the rate of healthcare-associated infections and the proportion of deaths related to these infections are unknown. This article describes the epidemiology of healthcare-associated infections among neonates in seven neonatal units located in three Brazilian cities.

\section{METHODS \\ Setting and Design}

Prospective surveillance of healthcare-associated infections in seven neonatal units was conducted from January 1, 1997, to December 31,1998 . The units were located in the cities of Rio de Janeiro, Campinas, and São Paulo, and the number of beds ranged from 5 to 55 . All units had conveniently located sinks with paper towels, and handwashing with an antiseptic soap (2\% chlorhexidine gluconate) was the standard procedure for hand hygiene. The ratio of nursing staff to neonates ranged from $1: 1$ to $1: 3$ for intensive care and $1: 2$ to $1: 4$ for intermediate care. All neonates admitted to the neonatal units for more than 24 hours were included in the study and were observed until discharge. Routine infection control measures in these units included active surveillance of healthcare-associated infections, advice on the management of infections, and regular training of

Drs. Pessoa-Silva, Santos, and Frota are from Universidade Federal do Rio de Janeiro, Rio de Janeiro; Dr. Richtmann and Ms. Costa are from Hospital e Maternidade Santa Joana, São Paulo; Dr. Calil is from UNICAMP/Universidade Estadual de Campinas; and Dr. Wey is from Universidade Federal de São Paulo, São Paulo, Brazil.

Address reprint requests to Carmem Lúcia Pessoa-Silva, MD, Service Prévention et Controle de l'Infection - UPCI, Hôpitaux Universitaires de Genève, 24, rue Micheli du Crest - CH-1211, Geneva 14, Switzerland.

Supported in part by Conselho Nacional de Desenvolvimento Científico e Tecnológico (CNPq), Brasília, grant no. 20.0694//99-5.

The authors thank Stéphane Hugonnet, MD, MS, from the Infection Control and Prevention Unit, University of Geneva Hospitals, Switzerland, for careful review of the manuscript.

Presented in part at the Fourth Decennial International Conference on Nosocomial and Healthcare-Associated Infections; March 5-9, 2000; Atlanta, GA 
TABLE 1

Healthcare-Associated infection Rates According to Birth Weight for Seven Neonatal Units in Brazil During 1997 to 1998

\begin{tabular}{|c|c|c|c|c|c|}
\hline & \multicolumn{4}{|c|}{ Birth Weight (g) } & \multirow[b]{2}{*}{ Total } \\
\hline & $\leqslant 1,000$ & 1,001 to 1,500 & 1,501 to 2,500 & $>2,500$ & \\
\hline No. of patients & 395 & 639 & 1,725 & 2,119 & 4,878 \\
\hline No. of patient-days & 10,866 & 15,936 & 19,093 & 14,153 & 60,048 \\
\hline $\begin{array}{l}\text { No. of HAIs } \\
\text { (maternal/hospital origin) }\end{array}$ & $\begin{array}{l}327 \\
(70 / 257)\end{array}$ & $\begin{array}{l}364 \\
(69 / 295)\end{array}$ & $\begin{array}{l}455 \\
(153 / 302)\end{array}$ & $\begin{array}{l}348 \\
(128 / 220)\end{array}$ & $\begin{array}{l}1,494 \\
(420 / 1,074)\end{array}$ \\
\hline No. of patients with HAI (\%) & $205(51.9)$ & $264(41.3)$ & $342(19.8)$ & $261(12.3)$ & $1,072(22.0)$ \\
\hline HAI cumulative incidence rate & 82.8 & 57.0 & 26.4 & 16.4 & 30.6 \\
\hline HAI incidence density rate & 30.1 & 22.8 & 23.8 & 24.6 & 24.9 \\
\hline
\end{tabular}

$\mathrm{HAl}=$ healthcare-associated infection.

personnel regarding standard, hospital infection control practices. Active surveillance was conducted by members of the hospital infection control team (Rio de Janeiro: CLP-S, RMRS, and ACCF; Campinas: RC; and São Paulo: RR and MLMC), who visited each unit at least three times a week and could always be reached (even on weekends) by cellular phones and pagers. These members were in close contact with unit staff. Healthcare-associated infections were identified through chart review, participation in ward rounds, and review of laboratory reports.

\section{Definitions and Data Collected}

For surveillance of healthcare-associated infections, we employed standard methods for surveillance and definitions from the high-risk nursery component of the National Nosocomial Infections Surveillance System. ${ }^{7,8}$ All infections, except those known or proved to have been acquired transplacentally (ie, herpes simplex, toxoplasmosis, rubella, cytomegalovirus, and syphilis), were considered to be healthcare associated. They were classified into two categories: infections occurring up to 48 hours after birth were considered healthcare-associated infections of maternal origin and those occurring after this point were considered healthcare-associated infections of hospital origin. ${ }^{9} \mathrm{~A}$ device-associated infection was defined as an infection in a neonatal patient with a device (ie, ventilator or central venous catheter [CVC]) that was used within 48 hours before the onset of the infection. ${ }^{10}$ If either signs or evidence of incubation of infection was already present when a device was inserted, the infection was not considered to be associated with the device. Death was considered related to healthcare-associated infection if it occurred during an active episode of infection. Data collected included number of patients in the neonatal unit, total number of patient-days, and device utilization in each of the four birth weight groups (group 1, 1,000 $\mathrm{g}$ or less; group 2,1,001 to $1,500 \mathrm{~g}$; group $3,1,501$ to $2,500 \mathrm{~g}$; and group 4 , more than $2,500 \mathrm{~g}$ ).

\section{Microbiologic Methods}

Specimens for culture were collected based on clinical criteria established by the medical staff. Blood samples were drawn through peripheral veins or arteries, inoculated onto Bactec-Plus (Becton Dickinson, Franklin Lakes, NJ) pediatric medium, and incubated for 120 hours. Clinical isolates were identified using the VITEK GNI card (VITEK system, bioMérieux, Inc., Hazelwood, $\mathrm{MO})$. An isolate was defined as a healthcare-associated infection pathogen if isolated from a sterile fluid (ie, blood, urine, cerebrospinal fluid, bronchoalveolar lavage with quantitative culture, or fluid or tissue aseptically obtained from a surgical incision) of a neonatal patient with signs of infection, as previously defined. ${ }^{8}$

\section{Rates, Ratios, and Statistical Procedures}

The overall incidence density rate for healthcareassociated infection was calculated by dividing the number of healthcare-associated infections by the total number of patient-days in the neonatal unit during the same period and then multiplying by 1,000 . The overall cumulative incidence rate for healthcare-associated infection was calculated by dividing the number of healthcare-associated infections by the total number of admitted patients in the neonatal unit during the same period and then multiplying by 100 . We calculated device-associated infection rates by dividing the number of cases of pneumonia or primary bloodstream infection (BSI) by the total number of respective device-days and then multiplying by 1,000 . The device utilization ratios for $\mathrm{CVCs}$ and ventilators were calculated by dividing the number of days of device use by the number of patient-days. All rates and ratios were stratified according to the four birth weight groups. Statistical analyses were performed using chi-square or Fisher's exact test, where appropriate.

\section{RESULTS}

From January 1, 1997, to December 31, 1998, 1,494 healthcare-associated infections were detected among 
TABLE 2

Distribution of Sites of Infection According to Birth Weight for Seven Neonatai. Units in Brazil. During 1997 to 1998

\begin{tabular}{|c|c|c|c|c|c|}
\hline \multirow[b]{2}{*}{ Site } & \multicolumn{4}{|c|}{ Blrth Woight (E) } & \multirow[b]{2}{*}{ Total (\%) } \\
\hline & $\leqslant 1,000(\%)$ & 1,001 to $1,500(\%)$ & 1,501 to $2,500(\%)$ & $>2,500$ & \\
\hline BSI & $206(63.0)$ & $177(48.6)$ & $229(50.3)$ & $142(40.8)$ & $754(50.5)$ \\
\hline Maternal origin & 58 & 59 & 105 & 74 & 296 \\
\hline Hospital origin & 148 & 118 & 124 & 68 & 458 \\
\hline Pneumonia & $41(12.5)$ & $34(9.3)$ & $71(15.6)$ & $75(21.6)$ & $221(14.8)$ \\
\hline Maternal origin & 12 & 9 & 45 & 51 & 117 \\
\hline Hospital origin & 29 & 25 & 26 & 24 & 104 \\
\hline Eye, ear, nose, and throat & $38(11.6)$ & $61(9.3)$ & $60(15.6)$ & $46(21.6)$ & 205 (13.7) \\
\hline Conjunctivitis & 21 & 29 & 32 & 20 & 102 \\
\hline Oral & 16 & 29 & 27 & 26 & 98 \\
\hline Other & 1 & 3 & 1 & 0 & 5 \\
\hline Skin and soft tissue & $17(5.1)$ & $37(10.1)$ & $32(7.0)$ & $26(7.5)$ & $112(7.5)$ \\
\hline Skin & 17 & 36 & 32 & 23 & 108 \\
\hline Other & 0 & 1 & 0 & 3 & 4 \\
\hline Gastrointestinal & $14(4.3)$ & $30(8.2)$ & $30(6.6)$ & $12(3.5)$ & $86(5.8)$ \\
\hline Necrotizing enterocolitis* & 13 & 18 & 18 & 8 & 57 \\
\hline Gastroenteritis & 0 & 12 & 10 & 2 & 24 \\
\hline Intra-abdominal & 1 & 0 & 2 & 2 & 5 \\
\hline Central nervous system ${ }^{\star}$ & $5(1.5)$ & $10(2.7)$ & $7(1.5)$ & $11(3.2)$ & $33(2.2)$ \\
\hline Surgical-site infection & $0(0)$ & $7(1.9)$ & $8(1.8)$ & $16(4.6)$ & $312.1)$ \\
\hline Urinary tract infection & $2(0.6)$ & $3(0.8)$ & $5(1.1)$ & $14(4.0)$ & $24(1.6)$ \\
\hline Cardiovascular system & $3(0.9)$ & $5(1.4)$ & $9(2.0)$ & $6(1.7)$ & $23(1.5)$ \\
\hline Other $^{\dagger}$ & $1(0.3)$ & $0(0)$ & $4(0.9)$ & $0(0)$ & $5(0.3)$ \\
\hline Total & $327(100)$ & $364(100)$ & $455(100)$ & $348(100)$ & $1,494(100)$ \\
\hline
\end{tabular}

BSI - bloodstream infection.

*Three cases of necrotizing enterocolitis, four cases of meningitis, and one case of disseminated infection were maternally acquired.

Three cases of disseminated infection, one case of ar thritis, and one case of tracheobronchitis.

4,878 neonates. Of these neonates, $1,072(22 \%)$ had at least one healthcare-associated infection (Table 1). The percentage of patients affected by at least one healthcareassociated infection ranged from $12.3 \%$ in group 4 to $51.9 \%$ in group $1(P<.001)$. The overall incidence density was 24.9 healthcare-associated infections per 1,000 patientdays, and group 1 had higher rates than did the other groups $(P<.001)$. Cumulative incidence rates ranged from 16.4 to 82.8 per 100 discharges, being higher among groups 1 and $2(P<.001)$. Almost 40\% (106 of 266$)$ of all deaths were related to healthcare-associated infection, although this relationship was more prominent among neonates of group 2 (21 of $35 ; 60.0 \%)$ than among the other groups of neonates ( 85 of $231 ; 36.8 \%)(P=.009)$.

\section{Sites of Infection}

The most frequent healthcare-associated infection in all birth weight groups was BSI, comprising 50.5\% (754 of 1,494) of all healthcare-associated infections (Table 2). BSI was more frequent among very low birth weight neonates $(<1,500 \mathrm{~g} ; 14.3 \mathrm{BSIs}$ per 1,000 patient-days) than among neonates weighing more (11.2 BSIs per 1,000 patient-days) $(P<.001)$. Only $13.2 \%$ (39 of 296$)$ of the BSls of maternal origin were laboratory confirmed, compared with 50\% (229 of 458) of the BSIs of hospital origin $(P<$ $.001)$. In all BSIs of maternal origin, signs of infection were already present or infection was in incubation when a CVC was inserted; therefore, they were not considered to be associated with the device. On the other hand, $47.8 \%$ (219 of 458) of the BSIs of hospital origin were associated with a CVC, and laboratory confirmation was more frequent when this device was in place: $60.3 \%$ (132 of 219$)$ in the presence of a CVC versus $40.6 \%$ (97 of 239) otherwise $(P<.001)$.

Pneumonia was the second most common healthcare-associated infection, accounting for $14.8 \%$ (221 of $1,494)$ of all healthcare-associated infections, and was more frequent among neonates of groups 3 and 4 (4.4 cases of pneumonia per 1,000 patient-days) than among very low birth weight neonates (2.8 per 1,000 patientdays) $(P<.001)$. Although ventilator-associated pneumonia comprised most $(80 \%)$ of the pneumonia of hospital origin, the proportion of pneumonia (21 of 104) not associated with such a device 48 hours after birth was nonetheless substantial.

Eye, ear, nose, and throat infections were third, fol- 
TABLE 3

Distribution of Healthcare-Assuciated Microorganisms Isolated From Sterile Fluids* According to Site of Infection ani) Time After Birth for Seven Neonatal. Units in Brazil. During 1997 to 1998

\begin{tabular}{|c|c|c|c|c|c|}
\hline \multirow[b]{2}{*}{ Microorganism } & \multicolumn{2}{|c|}{ BSI } & \multicolumn{2}{|c|}{ Other Sltes } & \multirow[b]{2}{*}{ Total } \\
\hline & $\leqslant \mathbf{4 8 h}$ & $>48 h$ & $\leqslant 48 h$ & $>48 \mathrm{~h}$ & \\
\hline Coagulase-negative staphylococci & 5 & 54 & 0 & 35 & 94 \\
\hline Enterobacter species & 1 & 52 & 0 & 7 & 60 \\
\hline Staphylococcus aureus & 0 & 39 & 0 & 17 & 56 \\
\hline Klebsiella species $^{\dagger}$ & 2 & 24 & 0 & 15 & 41 \\
\hline Group B Streptococcus agalactiae & 20 & 5 & 0 & 0 & 25 \\
\hline Candida species & 0 & 16 & 1 & 5 & 22 \\
\hline Escherichia coli & 5 & 8 & 1 & 5 & 19 \\
\hline Enterococcus faecalis & 3 & 9 & 1 & 1 & 14 \\
\hline Acinetobacter species & 0 & 11 & 0 & 0 & 11 \\
\hline Pseudomonas species ${ }^{\ddagger}$ & 0 & 8 & 0 & 3 & 11 \\
\hline Listeria monocytogenes & 3 & 1 & 0 & 0 & 4 \\
\hline Other nonfermentative gram-negative bacilli & 1 & 14 & 0 & 12 & 27 \\
\hline Other enteric bacilli & 0 & 5 & 1 & 10 & 16 \\
\hline Other Streptococcus species & 0 & 2 & 1 & 4 & 7 \\
\hline Others ${ }^{\S}$ & 0 & 1 & 1 & 1 & 3 \\
\hline Total & 40 & 249 & 6 & 115 & 410 \\
\hline
\end{tabular}

$\mathrm{BSI}=$ bloodstream infection.

`Blood, urine, cerebrospinal fluid, bronchoalveolar lavage with quantitative culture, and fluid or tissue aseptically obtained from a surgical incision.

${ }^{+}$Forty $K$. pneumoniae and $1 K$ oxytoca.

TTen $P$ aeruginosa and 1 Pseudomonas species.

'One Haemophilus influenzae, 1 Bacillus species, and 1 Rhodotorula species

lowed by skin and soft tissue and gastrointestinal infections. Conjunctivitis was the most prevalent eye, ear, nose, and throat infection. Necrotizing enterocolitis accounted for $66.3 \%$ of the gastrointestinal infections and it was even more prevalent among low birth weight neonates (birth weight, $<2,500 \mathrm{~g}$ ). Mucocutaneous candidiasis was a common infection in all groups, and oral thrush together with cutaneous candidiasis comprised $10.8 \%$ of all healthcareassociated infections.

\section{Healthcare-Associated Infections of Maternal Origin}

A large proportion of all healthcare-associated infections $(420$ of 1,$494 ; 28.1 \%)$ began within 48 hours after birth, and BSI and pneumonia accounted for $98.3 \%$ of these infections. As many as 39.3\% (296 of 754) of all BSIs and $52.9 \%$ (117 of 221) of all cases of pneumonia were maternally acquired. Interestingly, the proportion of healthcare-associated infections of maternal origin was much higher among neonates weighing more than 1,500 $\mathrm{g}$ at birth (281 of $803 ; 35 \%)$ than among very low birth weight neonates $(140$ of $691 ; 20.3 \%)(P<.001)$.

\section{Pathogen Distribution}

Microbiologic identification was possible for only $389(26 \%)$ of the healthcare-associated infections (268 BSIs and 121 healthcare-associated infections other than BSI). Twenty BSIs were polymicrobial: 19 with two pathogens and 1 with three pathogens. A higher proportion of healthcare-associated infections of hospital origin (344 of 1,074) had microbiologic identification as compared with those of maternal origin $(45$ of 420$)(P<.0001)$. Microorganisms isolated from sterile fluids are listed in Table 3 . The five main groups of pathogens were coagulase-negative staphylococci $(22.9 \%)$, Enterobacter species (14.6\%), Staphylococcus aureus (13.7\%), Klebsiella species $(10.0 \%)$, and group B Streptococcus (6.1\%). Gram-positive pathogens predominated, with coagulase-negative staphylococci as the leading microorganisms. During the study period there was an outbreak of extended-spectrum betalactamase-producing $K$. pneumoniae in one neonatal unit, ${ }^{11}$ contributing to 15 of the 41 cases of Klebsiella species infections. Group B Streptococcus accounted for $43.5 \%$ ( 20 of 46 ) of the causative agents of maternal origin, followed by Escherichia coli ( 6 of $46 ; 13.0 \%$ ), coagulasenegative staphylococci (5 of $46 ; 10.9 \%$ ), and Enterococcus faecalis ( 4 of $46 ; 8.7 \%$ ).

\section{Device-Associated Infection Rates}

A device was already in place before the incubation and the initiation of symptoms in all infections associated with a device, and all of these infections occurred 48 hours after birth. The distributions of device-associated infection rates and device utilization ratios are listed in Tables 4 and 5. Higher rates of CVC-associated BSI were observed in group $1(P<.001)$. These neonates also had a 
TABLE 4

Central Venous Catheter (CVC) Utilization Ratio and CVC-AsSOCIATED BLOODSTREAM INFECTION RATE ACCORDING TO Birth Weight for Seven Neonatal Units in Brazil During 1997 To 1998

\begin{tabular}{lcccc}
\hline $\begin{array}{l}\text { Birth } \\
\text { Wolght (g) }\end{array}$ & $\begin{array}{c}\text { No. of } \\
\text { Patlent- } \\
\text { Days }\end{array}$ & $\begin{array}{c}\text { No. of } \\
\text { CVC-Days }\end{array}$ & $\begin{array}{c}\text { DU } \\
\text { Ratio* }\end{array}$ & $\begin{array}{c}\text { CVc- } \\
\text { Associated } \\
\text { BsI Rate }\end{array}$ \\
\hline$\leqslant 1,000$ & 10,866 & 2,663 & 0.25 & 34.92 \\
1,001 to 1,500 & 15,936 & 1,909 & 0.12 & 20.43 \\
1,501 to 2,500 & 19,093 & 2,136 & 0.11 & 17.32 \\
$>2,500$ & 14,153 & 1,927 & 0.14 & 18.16 \\
\hline
\end{tabular}

$\mathrm{DU}$ - device utilization; $\mathrm{BSI}=$ bloodstream infection.

*Number of CVC-days divided by the number of patient-days.

${ }^{\dagger}$ Number of CVC-associated BSIs divided by the number of CVC-days and then multiplied by 1,000 .

higher device utilization rate for $\mathrm{CVCs}(P<.001)$. On the other hand, $\mathrm{CVC}$ use was statistically different among the other three groups, but the rates for CVC-associated BSI did not differ. Regarding ventilator-associated pneumonia, rates were similar for all groups, although device utilization rates varied among the groups.

\section{DISCUSSION}

This is the first multicenter study and the largest study regarding healthcare-associated infection among neonates in Brazil. Incidence density rates for healthcareassociated infection observed in this study were much higher than those observed in most studies in the United States or Europe, ${ }^{5,6,12-15}$ but similar to those in another Brazilian study. ${ }^{16}$ On the other hand, few studies include healthcare-associated infection of maternal origin in the surveillance of healthcare-associated infection. In a large series in the United States, almost $12 \%$ of all healthcareassociated infections were maternally acquired. ${ }^{9}$ In the current study, $28 \%$ of all healthcare-associated infections were of maternal origin. If only healthcare-associated infection of hospital origin had been considered for the calculation of rates, overall rates in this study would have been comparable to those in the previously mentioned studies from the United States and Europe. The unexpectedly high proportion of infections of maternal origin has also been documented by Kawagoe et al., ${ }^{16}$ and may be a local phenomenon that deserves further evaluation. In addition, this study confirmed that neonates with a birth weight of $1,500 \mathrm{~g}$ or less were a high-risk population for healthcare-associated infection, as shown in other regions. ${ }^{6,17}$

The distribution of sites was similar to that reported by others ${ }^{9}$ but different from that for adults in intensive care units. BSI was the main healthcare-associated infection in all birth weight groups, accounting for $50 \%$ of all infections in this study. The high proportion of BSIs represented a major concern because they are associated
TABLE 5

Ventilator UTILIzation Ratio and Ventilator-Associated Pneumonia Rate AcCordng to Birth Weight for SEven NeONATAL UnITS IN BrazIL DurINg 1997 to 1998

\begin{tabular}{lcccc}
\hline $\begin{array}{l}\text { BIrth } \\
\text { Welght (g) }\end{array}$ & $\begin{array}{c}\text { No. of } \\
\text { Patient- } \\
\text { Days }\end{array}$ & $\begin{array}{c}\text { No. of } \\
\text { Ventllator- } \\
\text { Days }\end{array}$ & $\begin{array}{c}\text { DU } \\
\text { Ratio* }\end{array}$ & $\begin{array}{c}\text { VAP } \\
\text { Rate }^{\dagger}\end{array}$ \\
\hline$\leqslant 1,000$ & 10,866 & 3,707 & 0.34 & 7.01 \\
1,001 to 1,500 & 15,936 & 2,286 & 0.14 & 9.19 \\
1,501 to 2,500 & 19,093 & 2,444 & 0.13 & 7.77 \\
$>2,500$ & 14,153 & 2,057 & 0.15 & 8.26 \\
\hline
\end{tabular}

$\mathrm{DU}=$ device utilization: VAP = ventilator-associated pneumonia.

*Number of ventilator-days divided by the number of patient-days.

${ }^{\mathrm{N}}$ Number of VAPs divided by the number of ventilator-days and then multiplied by 1,000 .

with increased mortality, prolonged length of hospital stay, and slower growth among very low birth weight infants. . $^{18-20}$

Rates of device-associated infections were extraordinarily high when compared with National Nosocomial Infections Surveillance System data ${ }^{21}$ and should be a target of surveillance and prevention efforts. The use of devices such as CVCs and mechanical ventilators had already been identified as an independent risk factor for healthcare-associated infection in our milieu, ${ }^{16}$ and the infection control program in these units had already implemented specific guidelines for the prevention of device-related infections. ${ }^{22,23}$ Regarding CVC-associated infections, greater device use was associated with a greater CVC-associated BSI rate, particularly among neonates weighing $1,000 \mathrm{~g}$ or less at birth. This finding may be due to a higher risk of BSI resulting from $\mathrm{CVC}$ use in this group. Surprisingly, greater ventilation use in the latter group was not associated with higher ventilatorassociated pneumonia rates, as compared with other birth weight groups.

Among the pathogens responsible for healthcareassociated infection of hospital origin, coagulase-negative staphylococci ranked first, similar to other reports. 5,9 Regarding the etiology of BSI, this pathogen comprised only $20.4 \%$ of the cases, whereas in other reports it was responsible for half of the cases..$^{5,9}$ Conversely, enteric bacilli were the main pathogen of BSI in this series, and a similar etiology has been observed in the southern hemisphere. ${ }^{17,24}$ Group B Streptococcus was not detected with the same frequency as in the United States, but it was the main pathogen responsible for maternally acquired BSI. Such a finding is worrisome because this pathogen is frequently underestimated in Brazil and no routine approach for prevention of perinatal group B streptococcal infection is currently recommended in this country. Five additional cases of group B streptococcal BSI occurred beyond 48 hours after birth. The definitions applied in the current study did not take into account the pathogen, and the latter infections were classified as infections of hospital origin. 
Pathogen identification was limited in this study. In particular, no regular surveillance for viral infections was conducted. Viruses may play an important role in gastrointestinal and eye, ear, nose, and throat infections. ${ }^{9}$ Another shortcoming of the current study is that microbiologic confirmation was relatively low, particularly for BSI of maternal origin. All of these units were provided with good laboratory support for bacteriologic identification, and laboratory constraints could not explain such a finding. On the other hand, BSIs and pneumonia accounted for a high proportion of healthcare-associated infections, and the identification of etiologic agents may be difficult among neonates. In the current series, clinical sepsis accounted for most episodes of BSI, contrary to the results reported by Gaynes et al. ${ }^{9}$ We performed on-site surveillance of healthcare-associated infections with prospective follow-up of all admitted patients; this surveillance strategy has been associated with a high sensitivity for BSI detection..$^{25}$ Furthermore, although standard definitions were applied, ${ }^{8}$ these referred to clinical sepsis in patients younger than 1 year and not specifically to the neonatal period. In particular, neonates admitted to neonatal intensive care units are frequently unstable during the first 48 hours after birth and their clinical manifestations make the differential diagnosis with non-infectious syndromes difficult. Despite the prospective clinical follow-up, the employment of the aforementioned definitions might have resulted in overestimation of BSIs in this series. These data suggest a compelling need for specific definitions for healthcare-associated infection during the neonatal period.

We observed a high frequency of healthcare-associated infections of maternal origin. On the one hand, this might denote issues in perinatal care in Brazil. On the other hand, this might denote the need for specific definitions for healthcare-associated infection during the neonatal period, especially during the first 48 hours after birth. Neonates weighing $1,500 \mathrm{~g}$ or less at birth and those who used a device were at increased risk for acquiring a healthcare-associated infection. These findings should be used to direct prevention and control efforts.

\section{REFERENCES}

1. Donowitz LG. Nosocomial infection in neonatal intensive care units. Am I Infect Control 1989;17:250-257.

2. Ford-Jones EL, Mindorff CM, Langley JM, et al. Epidemiologic study of 4,684 hospital-acquired infections in pediatric patients. Pediatr Infect Dis J 1989;8:668-675.

3. Daschner F. Analysis of bacterial infections in a neonatal intensive care unit. J Hosp Infect 1983;4:90-91.

4. Hoogkamp-Korstanje JA, Cats B, Senders RC, van Ertbruggen I. Analysis of bacterial infections in a neonatal intensive care unit. $J$ Hosp Infect 1982;3:275-284.

5. Raymond J, Aujard Y, Group ES. Nosocomial infections in pediatric patients: a European, multicenter prospective study. Infect Control Hosp Epidemiol 2000;20:260-263.

6. Sohn AH, Garrett DO, Sinkowitz-Cochran RL, et al. Prevalence of nosocomial infections in neonatal intensive care unit patients: results from the first national point-prevalence survey. J Pediatr 2001;139:821827

7. Gaynes RP, Horan TC. Surveillance of nosocomial infections. In: Mayhall G, ed. Hospital Epidemiology and Infection Control. Baltimore: Williams \& Wilkins; 1999:1285-1317.

8. Garner JS, Jarvis WR, Emori TG, Horan TC, Hughes JM. CDC definitions for nosocomial infections, 1988. Am J Infect Control 1988;16:128140.

9. Gaynes RP, Edwards JR, Jarvis WR, Culver DH, Tolson JS, Martone WJ. Nosocomial infections among neonates in high-risk nurseries in the United States. Pediatrics 1996;98(3 part 1):357-361.

10. Horan TC, Emori TG. Definitions of key terms used in the NNIS System. Am J Infect Control 1997;25:112-116.

11. Pessoa-Silva CL, Meurer Moreira B, Camara Almeida V, et al. Extended-spectrum beta-lactamase-producing Klebsiella pneumoniae in a neonatal intensive care unit: risk factors for infection and colonization. J Hosp Infect 2003;53:198-206.

12. Hemming VG, Overall JC Jr, Britt MR. Nosocomial infections in a newborn intensive-care unit: results of forty-one months of surveillance. $N$ Engl J Med 1976;294:1310-1316.

13. Josephson A, Karanfil L, Alonso H, Watson A, Blight J. Risk-specific nosocomial infection rates. Am J Med 1991:91 (suppl 3B):131S-137S.

14. Maguire GC, Nordin J, Myers MG, Koontz FP, Hierholzer W, Nassif E. Infections acquired by young infants. Am J Dis Child 1981;135:693-698.

15. Moro ML, De Toni A, Stolf I, Carrieri MP, Braga M, Zunin C. Risk factors for nosocomial sepsis in newborn intensive and intermediate care units. Eur J Pediatr 1996;155:315-322.

16. Kawagoe JY, Segre CA, Pereira CR, Cardoso MF, Silva CV, Fukushima JT. Risk factors for nosocomial infections in critically ill newborns: a 5 year prospective cohort study. Am J Infect Control 2001:29:109-114.

17. Ho JJ. Late onset infection in very low birth weight infants in Malaysian level 3 neonatal nurseries. Pediatr Infect Dis J 2001;20:557560 .

18. Ehrenkranz RA, Younes N, Lemons JA, et al. Longitudinal growth of hospitalized very low birth weight infants. Pediatrics 1999;104:280-289.

19. Pessoa-Silva CL, Miyasaki CH, de Almeida MF, Kopelman BI, Raggio RL. Wey SB. Neonatal late-onset bloodstream infection: attributable mortality, excess of length of stay and risk factors. Eur J Epidemiol 2001;17:715-720.

20. Townsend TR, Wenzel RP. Nosocomial bloodstream infections in a newborn intensive care unit: a case-matched control study of morbidity, mortality and risk. Am J Epidemiol 1981;114:73-80.

21. National Nosocomial Infections Surveillance (NNIS) System. National Nosocomial Infections Surveillance (NNIS) System report: data summary from January 1992-June 2001, issued August 2001. Am J Infect Control 2001;29:404-421.

22. Pearson ML. Guideline for prevention of intravascular device-related infections. Infect Control Hosp Epidemiol 1996;17:438-473.

23. Centers for Disease Control and Prevention. Guidelines for prevention of nosocomial pneumonia. $M M W R$ 1997;46(RR-1):1-79.

24. Stoll BJ. The global impact of neonatal infection. Clin Perinatol 1997;24:1-21.

25. Hugonnet S, Sax H, Eggimann P, Chevrolet J-C, Pittet D. Nosocomial bloodstream infection and clinical sepsis. Emerg Infect Dis 2004;10:7681. 